\title{
ANALISIS PENGAKUAN PENDAPATAN DAN PENCATATAN AKUNTANSI PAJAK BUMI DAN BANGUNAN PERDESAAN DAN PERKOTAAN PADA BADAN PENGELOLA PAJAK DAN RETRIBUSI DAERAH KOTA BITUNG
}

\author{
Selint Gar Andea ${ }^{1}$, Jullie J. Sondakh ${ }^{2}$, Novi Swandari Budiarso ${ }^{3}$ \\ 1,2,3 Jurusan Akuntansi, Fakultas Ekonomi dan Bisnis, Universitas Sam Ratulangi, Jl. Kampus Bahu, Manado, \\ 95115, Indonesia \\ E-mail: selintgarandea@gmail.com
}

\begin{abstract}
Land and Building Tax is a state tax imposed on land and or buildings in accordance with Law Number 12 of 1994. The purpose of this study is to determine whether revenue recognition and accounting records of $P B B-P 2$ at the Regional Tax and Retribution Management Agency city of Bitung is in accordance with Government Regulation Number 71 Year 2010. This study uses descriptive qualitative research where primary data obtained directly will then be analyzed, so that the results obtained can answer the main purpose of this study. The results show that recognition of tax revenue in Bitung City BPPRD which included, among others, recognition of tax revenue-LRA (Budget Realization Report), recognition of tax-LO income (Operational Report) and recording of PBB-P2 accounting at BPPRD in Bitung, had going well and in accordance with Law Number 71 of 2010.
\end{abstract}

Keywords: revenue recognition; accounting recording; $P B B-P 2$

\section{PENDAHULUAN}

Pajak adalah salah satu sumber penerimaan negara terbesar dan yang paling utama. Saat ini pemerintah daerah dituntut untuk berperan aktif dalam proses pembangunan nasional. Hal ini mendorong pemerintah daerah untuk meningkatkan penerimaan daerah dan melakukan pengelolaan keuangan dengan baik yang tercermin dalam Anggaran Pendapatan dan Belanja Daerah (APBD) disetiap periode. Pemerintah daerah diharapkan dapat mencari jalan keluar terhadap masalah perpajakan yang dihadapi, terutama tentang kesadaran masyarakat untuk membayar pajak dan mendorong agar berperan aktif dalam pemenuhan kewajiban perpajakan (Putra, 2015).

Salah satu jenis pajak yang dipungut oleh daerah menurut Undang-Undang Nomor 28 Tahun 2009 adalah Pajak Bumi dan Bangunan Perdesaan dan Perkotaan (PBB-P2). Pengalihan pengelolaan PBB-P2 dari pemerintah pusat ke pemerintah daerah, memberikan manfaat dan permasalahan tersendiri bagi daerah. Manfaat bagi pemerintah daerah adalah meningkatkan Pendapatan Asli Daerah (PAD) dan memperbaiki struktur APBD, sedangkan permasalah yang dihadapi adalah pengelolaan penerimaan pajak tersebut terkait pengakuan dan pencatatan akuntansi PBB-P2.

Peraturan Pemerintah Nomor 71 Tahun 2010 tentang Standar Akuntansi Pemerintahan (SAP) menyebutkan bahwa basis akuntansi yang digunakan dalam laporan keuangan pemerintah adalah basis akrual, untuk pengakuan pendapatan-LO (Laporan Operasional), beban, aset, kewajiban dan ekuitas diakui dan dicatat pada saat terjadinya transaksi, atau pada saat kejadian atau kondisi lingkungan berpengaruh pada keuangan pemerintah, tanpa memperhatikan saat kas atau setara kas diterima atau dibayar. Basis akrual untuk LO berarti bahwa pendapatan diakui pada saat hak untuk memperoleh pendapatan telah terpenuhi walaupun kas belum diterima di Rekening Kas Umum Daerah (RKUD) atau oleh entitas pelaporan dan beban diakui pada saat kewajiban yang mengakibatkan penurunan nilai 
kekayaan bersih, telah terpenuhi walaupun kas belum dikeluarkan dari RKUD atau entitas pelaporan. Anggaran disusun dan dilaksanakan berdasarkan basis kas, maka Laporan Realisasi Anggaran (LRA) disusun berdasarkan basis kas, berarti bahwa pendapatan dan penerimaan pembiayaan diakui pada saat kas diterima di RKUD atau oleh entitas pelaporan, serta belanja, transfer dan pengeluaran pembiayaan diakui saat kas dikeluarkan dari RKUD.

Pajak Bumi dan Bangunan Perdesaan dan Perkotaan (PBB-P2) yang awalnya merupakan pajak yang kewenangannya ada pada pemerintah pusat kemudian dialihkan menjadi pajak daerah. Berlakunya undang-undang tersebut, menjadikan Pajak Bumi dan Bangunan Perdesaan dan Perkotaan yang selanjutnya disebut PBB-P2 dari pajak pusat menjadi pajak daerah, serta diharapkan mampu menjadi salah satu sumber penerimaan PAD yang potensial bagi setiap daerah. Kewenangan dalam kegiatan yang terkait dengan PBB-P2 menjadi milik pemerintah daerah, hal ini meliputi proses pendataan, penilaian, penetapan, pengadministrasian, pemungutan/penagihan dan pelayanan terkait PBB-P2. Di Kota Bitung sendiri, pelimpahan kewenangan ini merupakan peluang sekaligus tantangan bagi pemerintah Kota Bitung, dalam meningkatkan kemampuan fiskal ataupun kemampuan keuangan pemerintah daerah. Pengalihan pengelolaan PBB-P2 ini dapat memperkecil kebutuhan akan bantuan dari pemerintah pusat dan dapat menjadi sumber utama pendapatan dari daerah itu sendiri (Ratuela et al., 2015). Kemandirian keuangan pemerintah daerah dapat membantu meningkatkan pelayanan publik. Pemerintah perlu melakukan perbaikan dan penyempurnaan dalam bidang keuangan daerah, yang harus dikelola secara efektif dan efisien baik dari pengakuan perpajakan dan pencatatan, khususnya PBB-P2 pada Badan Pengelola Pajak dan Retribusi Daerah (BPPRD) Kota Bitung.

\section{TINJAUAN PUSTAKA}

Menurut Wirawan dan Suhartono (2018:472), pajak merupakan kewajiban pembayaran oleh wajib pajak yang dibayar masyarakat kepada negara sesuai dengan peraturan perundangan-undangan yang sudah ditetapkan, tetapi masyarakat tidak mendapat balasan jasa yang dirasakan secara langsung, serta akan dipergunakan untuk membuat masyarakat di negara itu dapat memperoleh kesejahteraan. Pajak dikatakan sebagai instrumen yang sangat vital dan sumber pendapatan utama bagi pemerintah (Mansor dan Gurama, 2016). Menurut Mardiasmo (2016:1-2), pajak adalah sejumlah uang rakyat yang dibayarkan kepada negara, berdasarkan undang-undang yang bisa dipaksa dengan tidak mendapatkan imbalan yang langsung dirasakan, dan juga dipakai dalam membiayai pengeluaran umum. Pudihang et al. (2017) menyatakan bahwa akuntansi pajak adalah suatu proses pencatatan, penggolongan, dan pengikhtisaran suatu transaksi keuangan kaitannya dengan kewajiban perpajakan dan diakhiri dengan pembuatan laporan keuangan fiskal sesuai dengan ketentuan dan peraturan perpajakan yang terkait sebagai dasar pembuatan surat pemberitahuan tahunan. Menurut Mardiasmo (2018:389), PBB-P2 adalah pajak atas bumi dan/atau bangunan yang dimiliki, dikuasai dan/atau dimanfaatkan oleh orang pribadi atau badan, kecuali kawasan yang digunakan untuk kegiatan usaha Perkebunan, Perhutanan dan Pertambangan (P3), sedangkan untuk sektor usaha perkebunan, perhutanan, pertambangan, dan usaha tertentu lainnya masih dipungut oleh pemerintah pusat (Tambingon et al., 2019).

Menurut Wilson et al. (2015:4), akuntansi adalah proses pengumpulan, pengklasifikasian, pencatatan, pelaporan, penginterpretasian dan analisis dampak dari transaksi keuangan pada suatu bisnis atau organisasi, untuk menyediakan informasi kepada pemilik manajemen dan pihak yang membutuhkan lainnya. Menurut Kieso et al. (2016:2), akuntansi memiliki tiga karakter penting yaitu pengidentifikasi, pengukuran dan pengkomunikasian tentang informasi keuangan kepada pihak internal dan eksternal yang membutuhkan laporan keuangan. Pengidentifikasian peristiwa ekonomi dilakukan sesuai dengan kegiatan usaha dan pencatatan peristiwa dari perusahaan, untuk mempersiapkan dan 
menyajikan catatan kegiatan keuangan. Proses dalam mencatat dilakukan dengan sistematis, kronologis setiap peristiwa, dan dalam satuan mata uang. Pengkomunikasian kumpulan informasi kepada pihak internal dan eksternal atau pihak yang memerlukan dalam bentuk laporan akuntansi dikenal dengan laporan keuangan.

Menurut Siregar et al. (2018), pengakuan pendapatan adalah pencatatan suatu jumlah Rupiah (biaya) ke dalam sistem akuntansi sehingga jumlah tersebut akan mempengaruhi suatu pos dan tercermin dalam laporan keuangan. Jadi pengakuan berhubungan dengan masalah apakah suatu transaksi dicatat atau tidak. Standar akuntansi mengatur tentang pengakuan ini dengan memberikan beberapa kriteria pengakuan yaitu syarat-syarat apakah yang harus dipenuhi agar suatu transaksi dapat diakui serta saat pengakuan. Pengakuan pendapatan pajak daerah-LO dengan self assessment system diakui pada saat realisasi kas diterima oleh bendahara penerimaan atau di rekening kas daerah tanpa terlebih dahulu pemerintah daerah menerbitkan ketetapan. Pengakuan pendapatan pajak daerah-LO yang dipungut dengan official assessment system diakui pada saat timbulnya hak untuk menagih pendapatan pajak. Timbulnya hak menagih tersebut adalah pada saat diterbitkan ketetapan (Buletin teknis nomor 24). Menurut Napitupulu dan Budiarso (2015), pengakuan pendapatan memperhatikan sumber, sifat dan prosedur penerimaan pendapatan maka dapat diklasifikasikan ke dalam beberapa alternatif, yaitu pengakuan pendapatan ketika pendapatan diakui dengan adanya penetapan terlebih dahulu (official assessment) dan pengakuan pendapatan yang diakui dengan penghitungan sendiri oleh wajib pajak (self assessment).

Berdasarkan Peraturan Pemerintah Nomor 71 Tahun 2010, pendapatan-LRA diukur dan dicatat berdasarkan azas bruto, yaitu dengan membukukan penerimaan bruto, dan tidak mencatat jumlah netonya (setelah dikompensasikan dengan pengeluaran). Pendapatan-LO juga dilaksanakan berdasarkan azas bruto, yaitu dengan membukukan pendapatan bruto, dan tidak mencatat jumlah netonya (setelah dikompensasikan dengan pengeluaran). Malomis dan Wangkar (2015) mengungkapkan bahwa pengakuan pendapatan pihak ketiga didahului dengan adanya penetapan terlebih dahulu (official assessment) pencatatan jurnalnya adalah sebagai berikut:

1. Saat Badan Pengelola Pajak mengeluarkan Surat Pemberitahuan Pajak Terutang (SPPT) kepada wajib pajak:

Piutang Pajak Bumi dan Bangunan (PBB) XXX

Pendapatan PBB/Laporan Operasional/LO XXX

(Jurnal LO atau Neraca)

2. Saat menerima pembayaran atas Pajak Bumi dan Bangunan PBB:

Kas di Bendahara Penerimaan

Piutang PBB

XXX

(Jurnal LO atau Neraca)

Perubahan SAL

XXX

Pendapatan PBB-LRA

$\mathrm{XXX}$

Jurnal LRA)

3. Penyetoran pendapatan ke kas daerah:

R/K PPKD XXX

Kas di bendahara penerimaan $\quad$ XXX

(Jurnal LO atau Neraca) 
4. Jika wajib pajak melakukan pembayaran langsung ke rekening kas daerah:

$\mathrm{R} / \mathrm{K}$ PPKD $\quad \mathrm{XXX}$

PBB

XXX

(Jurnal LO atau Neraca)

Pendapatan Saldo Anggaran Lebih/SAL

Pendapatan PBB-LRA

XXX

(Jurnal LRA)

\section{METODE PENELITIAN}

Jenis penelitian ini adalah penelitian kualitatif dengan pendekatan metode deskriptif yaitu menyajikan data-data yang dapat memberikan gambaran secara umum tentang Pengakuan Pendapatan dan Pencatatan Akuntansi PBB-P2 pada BPPRD Kota Bitung sesuai dengan Peraturan Pemerintah Nomor 71 Tahun 2010 tentang SAP. Penelitian ini dilakukan di BPPDR kota Bitung yang beralamat di Jln. Sam Ratulangi Nomor 45, Kelurahan Bitung Tengah.

Sumber data yang digunakan pada penelitian ini adalah data primer. Data primer dalam penelitian ini adalah hasil wawancara langsung dengan Kepala BPPRD Kota Bitung, Kepala Bidang PBB-P2 dan BPHTB, dan Kepala Bidang Pencatatan Akuntansi. Penelitian ini menggunakan metode pengumpulan data dalam bentuk wawancara, dokumentasi dan kepustakaan. Penelitian ini menganalisis pengakuan pendapatan dan pencatatan akuntansi PBB-P2 pada BPPRD Kota Bitung.

\section{HASIL PENELITIAN DAN PEMBAHASAN}

\subsection{Hasil penelitian}

Pengakuan pendapatan-LRA, LO dan Pencatatan Akuntansi PBB-P2 pada BPPRD

Kota Bitung berdasarkan Peraturan Pemerintah Nomor 71 Tahun 2010 tentang SAP dijabarkan sebagai berikut:

1. Pendapatan LRA diakui pada saat:

a. Kas atas pendapatan tersebut telah diterima pada RKUD. Kas atas pendapatan tersebut telah diterima oleh bendahara penerimaan dan hingga tanggal pelaporan belum disetorkan ke RKUD, dengan ketentuan bendahara penerimaan tersebut merupakan bagian dari Bendahara Umum Daerah (BUD).

b. Kas atas pendapatan tersebut telah diterima Satuan Kerja Perangkat Daerah (SKPD) dan digunakan langsung tanpa disetor ke RKUD, dengan syarat entitas penerima wajib melaporkannya kepada BUD.

c. Kas atas pendapatan yang berasal dari hibah langsung dalam/luar negeri yang digunakan untuk mendanai pengeluaran entitas telah diterima, dengan syarat entitas penerima wajib melaporkannya kepada BUD.

d. Kas atas pendapatan yang diterima entitas lain, diluar entitas pemerintah berdasarkan otoritas yang diberikan oleh BUD, dan BUD mengakuinya sebagai pendapatan.

2. Pendapatan LO diakui pada saat:

a. Timbulnya hak atas pendapatan (earned); atau

b. Pendapatan direalisasi yaitu aliran masuk sumber daya ekonomi (realized).

3. Pencatatan akuntansi PBB-P2 di SKPD:

a. Saat Badan Pengelola Pajak mengeluarkan Surat Pemberitahuan Pajak Terutang (SPPT) kepadaWajib Pajak.

Piutang PBB-P2 13.674.516.635,00

Pendapatan PBB-P2 LO

13.674.516.635,00

(Jurnal LO atau Neraca) 
b. Saat menerima pembayaran atas PBB-P2.

Kas di Bendahara Penerimaan

$65.322,00$

Piutang PBB-P2

$65.322,00$

(Jurnal LO atau Neraca)

Perubahan Saldo Anggaran Lebih (SAL) 65.322,00

Pajak Bumi dan Bangunan

PBB-P2 - LRA

$65.322,00$

(Jurnal LRA)

c. Penyetoran pendapatan ke kas daerah.

R/K PPKD

$65.322,00$

Kas di bendahara penerimaan

(Jurnal LO atau Neraca)

d. Jika wajib pajak melakukan pembayaran langsung ke rekening kas daerah.

R/K PPKD

Piutang Pajak Bumi dan Bangunan

(Jurnal LO atau Neraca)

Perubahan Saldo Anggaran Lebih/SAL Pendapatan PBB-P2-LRA

(Jurnal LRA)
11.610.767.642

11.610 .767 .642

11.610.767.642

11.610.767.642

\subsection{Pembahasan}

Tabel 1 menunjukkan perbandingan penyajian pengakuan pendapatan-LRA antara BPPRD kota Bitung dan Peraturan Pemerintah Nomor 71 Tahun 2010 tentang SAP.

Tabel 1. Perbandingan penyajian pengakuan pendapatan-LRA antara BPPRD kota Bitung dan Peraturan Pemerintah Nomor 71 Tahun 2010

\begin{tabular}{|c|c|c|c|c|}
\hline No. & $\begin{array}{l}\text { Peraturan Pemerintah Nomor } 71 \\
\text { Tahun 2010 tentang SAP }\end{array}$ & Hasil Penelitian & Pembahasan & Keterangan \\
\hline 1. & $\begin{array}{l}\text { Pendapatan kas yang telah diterima } \\
\text { pada Rekening Kas Umum Daerah } \\
\text { (RKUD) }\end{array}$ & $\begin{array}{l}\text { Kas atas pendapatan } \\
\text { tersebut telah diterima } \\
\text { pada Rekening Kas } \\
\text { Umum Daerah } \\
\text { (RKUD) }\end{array}$ & $\begin{array}{l}\text { Pengakuan pendapatan- } \\
\text { LRA pada BPPRD di } \\
\text { kota Bitung sudah } \\
\text { sesuai, yaitu diakui pada } \\
\text { saat pendapatan kas } \\
\text { telah diterima pada } \\
\text { Rekening Kas Umum } \\
\text { Daerah (RKUD) }\end{array}$ & Sesuai \\
\hline 2. & $\begin{array}{l}\text { Kas atas pendapatan tersebut telah } \\
\text { diterima oleh bendahara penerimaan } \\
\text { dan hingga tanggal pelaporan belum } \\
\text { disetorkan ke RKUD, dengan } \\
\text { ketentuan bendahara penerimaan } \\
\text { tersebut merupakan bagian dari } \\
\text { Bendahara Umum Daerah (BUD) }\end{array}$ & $\begin{array}{l}\text { Pendapatan kas yang } \\
\text { telah diterima oleh } \\
\text { bendahara penerimaan } \\
\text { sebagai pendapatan } \\
\text { daerah dan hingga } \\
\text { tanggal pelaporan } \\
\text { belum disetorkan ke } \\
\text { RKUD, dengan } \\
\text { ketentuan bendahara } \\
\text { penerimaan tersebut } \\
\text { merupakan bagian } \\
\text { dari BUD }\end{array}$ & $\begin{array}{l}\text { Pengakuan pendapatan- } \\
\text { LRA pada BPPRD di } \\
\text { kota Bitung sudah } \\
\text { sesuai, yaitu diakui pada } \\
\text { saat kas atas pendapatan } \\
\text { telah diterima oleh } \\
\text { bendahara penerimaan } \\
\text { sebagai pendapatan } \\
\text { daerah dan hingga } \\
\text { tanggal pelaporan } \\
\text { disetorkan ke RKUD, } \\
\text { dengan ketentuan } \\
\text { bendahara penerimaan } \\
\text { tersebut merupakan } \\
\text { bagian dari BUD }\end{array}$ & Sesuai \\
\hline 3. & $\begin{array}{l}\text { Pendapatan kas yang diterima Satuan } \\
\text { Kerja Perangkat Daerah (SKPD) dan } \\
\text { digunakan langsung tanpa disetor ke }\end{array}$ & $\begin{array}{l}\text { Kas atas pendapatan } \\
\text { tersebut telah diterima } \\
\text { satker/SKPD dan }\end{array}$ & $\begin{array}{l}\text { Pengakuan pendapatan- } \\
\text { LRA pada BPPRD di } \\
\text { kota Bitung sudah sesuai }\end{array}$ & Sesuai \\
\hline
\end{tabular}




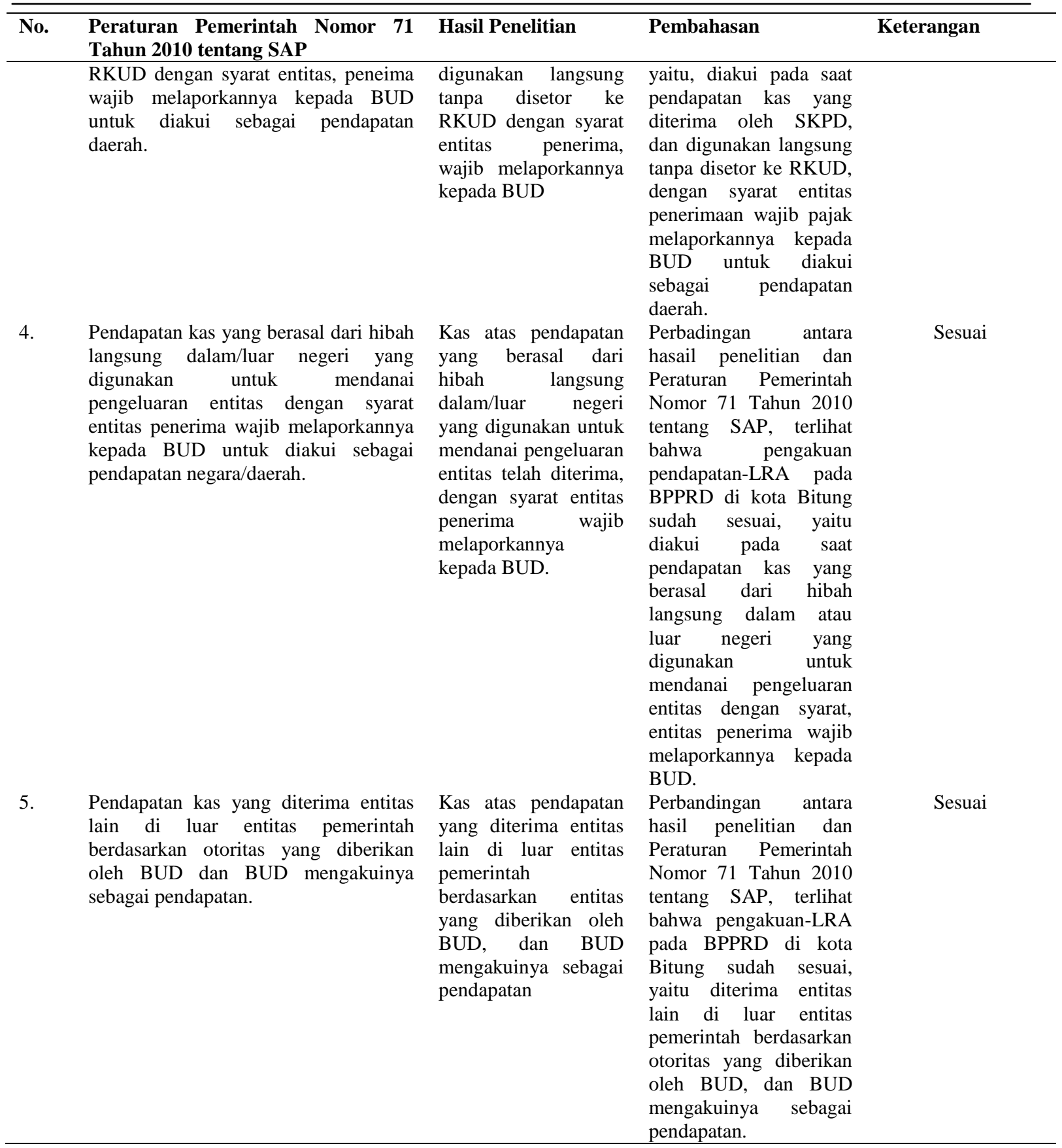

Sumber: Data hasil olahan, 2019

Tabel 2 menunjukkan perbandingan penyajian pengakuan pendapatan-LO antara BPPRD kota Bitung dan Peraturan Pemerintah Nomor 71 Tahun 2010 tentang SAP. 
Tabel 2. Perbandingan penyajian pengakuan pendapatan-LO antara BPPRD kota Bitung dan Peraturan Pemerintah Nomor 71 Tahun 2010

\begin{tabular}{|c|c|c|c|c|}
\hline No. & $\begin{array}{l}\text { Peraturan Pemerintah Nomor } 71 \\
\text { Tahun } 2010 \text { tentang SAP }\end{array}$ & Hasil Penelitian & Pembahasan & Keterangan \\
\hline 1. & Timbulnya hak atas pendapatan. & $\begin{array}{l}\text { Timbulnya hak atas } \\
\text { pendapatan (earned). }\end{array}$ & 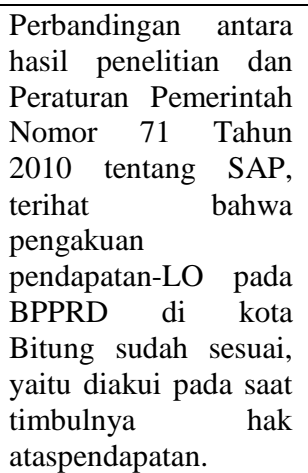 & Sesuai \\
\hline 2. & $\begin{array}{l}\text { Pendapatan direalisasi, yaitu adanya } \\
\text { aliran masuk sumber daya ekonomi. }\end{array}$ & $\begin{array}{l}\text { Pendapatan } \\
\text { direalisasi, yaitu } \\
\text { aliran masuk sumber } \\
\text { daya } \\
(\text { realized) }\end{array}$ & $\begin{array}{lr}\text { Perbandingan } & \text { antara } \\
\text { hasil peneitian dan } \\
\text { Peraturan Pemerintah } \\
\text { Nomor } 71 \text { Tahun } \\
2010 \text { tentang } \text { SAP, } \\
\text { terlihat } & \text { bahwa } \\
\text { pengakuan } & \\
\text { pendapatan-LO pada } \\
\text { BPPRD kota } & \text { Bitung } \\
\text { sudah sesuai, yaitu } \\
\text { diakui pada saat } \\
\text { pendapatan } \\
\text { direalisasi, } \\
\text { adanya aliran masuk } \\
\text { sumber yaitu } \\
\text { ekonomi. }\end{array}$ & Sesuai \\
\hline
\end{tabular}

Sumber: Data hasil olahan, 2019

Tabel 3 menunjukkan bahwa pengakuan Pencatatan Akuntansi PBB-P2 pada BPPRD kota Bitung telah sesuai dengan Peraturan Pemerintah Nomor 71 Tahun 2010 tentang SAP.

Tabel 3. Perbandingan penyajian pencatatan akuntansi PBB-P2 antara SKPD kota Bitung dan Peraturan Pemerintah Nomor 71 Tahun 2010 tentang SAP

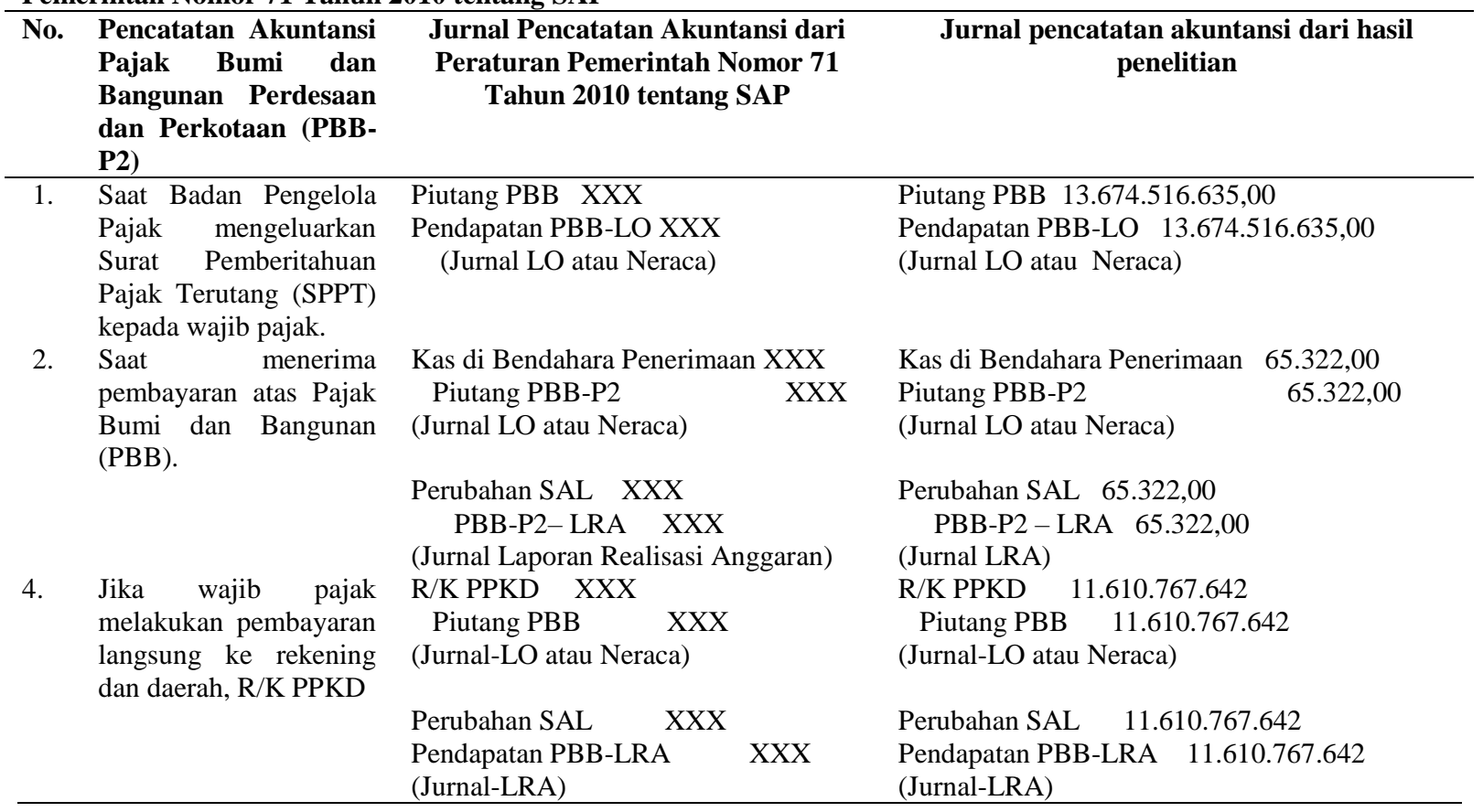

Sumber: Data hasil olahan, 2019 


\section{KESIMPULAN DAN SARAN}

\subsection{Kesimpulan}

Berdasarkan hasil penelitian dan pembahasan maka dapat disimpulkan bahwa, pengakuan pendapatan-LRA, pengakuan pendapatan-LO dan pencatatan akuntansi PBB-P2 pada BPPRD di kota Bitung, secara umum sudah diterapkan sesuai dengan Peraturan Pemerintah Nomor 71 Tahun 2010 tentang SAP.

\subsection{Saran}

Secara keseluruhan pengakuan pendapatan dan pencatatan akuntansi PBB-P2 pada BPPRD kota Bitung sudah sesuai dengan Peraturan Pemerintah Nomor 71 Tahun 2010 tentang SAP sehingga saran yang diberikan adalah:

1. BPPRD Kota Bitung terus mempertahankan apa yang sudah dilaksanakan yaitu melakukan pengakuan pendapatan dan pencatatan akuntansi PBB-P2 sesuai dengan Peraturan Pemerintah Nomor 71 Tahun 2010 tentang SAP.

2. BPPRD Kota Bitung kiranya terus menjaga sistem kinerja agar terus baik sesuai dengan peraturan dan ketentuan yang berlaku.

3. Kualitas dan kuantitas sumber daya manusia yang mengelola PBB-P2 sebaiknya perlu lebih ditingkatkan lagi, misalnya penambahan jumlah petugas karena jumlah yang ada saat ini masih kurang. Meningkatnya pelayanan dalam mengelola pendapatan PBB-P2 akan mempengaruhi tingkat pencapaian dan realisasi bagi daerah.

\section{DAFTAR PUSTAKA}

Buletin Teknis Nomor 24. Akuntansi pendapatan perpajakan. Komite Standar Akuntansi Pemerintahan (KSAP). http://www.ksap.org/sap/wp-content/uploads/2012/08/BultekPendapatan-Perpajakan-14062017-final.pdf

Kieso, D. E., Weigandt, J. J., \& Warfield, T. D. (2016). Akuntansi keuangan menengah: Akuntansi intermediate. Edisi IFRS. Jakarta: Salemba Empat.

Malomis, M, C., \& Wangkar, A. (2015). Analisis pemungutan dan pencatatan akuntansi PBB Pedesaan dan Perkotaan (PBB-P2) sebagai pajak daerah di Kota Tomohon. Jurnal EMBA: Jurnal Riset Ekonomi, Manajemen, Bisnis dan Akuntansi, 3(2), 103-113. https://ejournal.unsrat.ac.id/index.php/emba/article/view/8360

Mansor, M., \& Gurama, Z. (2016). The determinants of tax evasion in Gombe State Nigeria. International Journal of Economics and Financial Issues, 6(7S), 165-170. https://www.econjournals.com/index.php/ijefi/article/view/3601

Mardiasmo. (2016). Perpajakan Edisi Terbaru 2016. Yogyakarta: Andi.

Mardiasmo. (2018). Perpajakan Edisi Terbaru 2018. Yogyakarta: Andi.

Napitupulu, S, L., \& Budiarso, N. (2015). Pajak Bumi dan Bangunan Perdesaan dan Perkotaaan (PBB-P2) sebagai Pajak daerah dan implikasinya terhadap pencatatan akuntansi pada Pemerintahan Kota Manado. Jurnal EMBA: Jurnal Riset Ekonomi, Manajemen, Bisnis dan Akuntansi, 3(1), 463-472. https://ejournal.unsrat.ac.id/index.php/emba/article/view/7157

Pudihang, S., Morasa, J., \& Gamaliel, H. (2017). Mekanisme pemungutan pajak atas pemindahan hak pada jual beli tanah dan bangunan di Kabupaten Kepulauan Siau Tagulandang Biaro (Sitaro). Going Concern: Jurnal Riset Akuntansi, 12(1), 272-283. https://doi.org/10.32400/gc.12.01.17220.2017

Putra, E. T. (2015). Pengaruh efektivitas Pajak Bumi dan Bangunan Perdesaan dan Perkotaan (PBB-P2) terhadap Pendapatan Asli Daerah (PAD) pada Kabupaten/Kota di ProvinsiJawa Barat. Skripsi. http://repository.unpas.ac.id/id/eprint/13657 
Ratuela, J. G., Nangoi, B. G., \& Sabijono, H. (2015). Evaluasi pelaksanaan pemungutan dan prosedur pencatatan Pajak Bumi dan Bangunan Perdesaan dan Perkotaan (PBB-P2) sebagai pajak daerah di Kota Bitung. Jurnal Berkala Ilmiah Efisiensi,15(5), 34-45. https://ejournal.unsrat.ac.id/index.php/jbie/article/view/9693

Republik Indonesia, Peraturan Pemerintah nomor 71 tahun 2010 tentang Standar Akuntansi Pemerintahan.

Republik Indonesia, Undang-Undang Nomor 28 tahun 2009 tentang Pajak Daerah dan Retribusi Daerah.

Siregar, A. G. (2018). Penerapan pengakuan pendapatan dan beban pada PD. Pasar Kota Medan. Skripsi. http://repository.uinsu.ac.id/id/eprint/5104

Tambingon, V., Manossoh, H., \& Budiarso, N. S. (2019). Analisis strategi penerimaan Pajak Bumi dan Bangunan Pedesaan dan Perkotaan (PBB-P2) serta efektivitas penerimaannya di Pemerintah Kabupaten Minahasa Selatan Tahun 2016-2017. Going Concern : Jurnal Riset Akuntansi, 14(1), 80-88. https://doi.org/10.32400/gc.14.1.22290.2019

Wilson, V., Freeman, S., \& Freeman, J. (2015). Accounting: A practical approach. Australia: Pearson Higher Education.

Wirawan, B. I., \& Suhartono, R. (2018). Perpajakan: Pembahasan lengkap berdasarkan perundang-undangan dan aturan pelaksanaan terbaru Edisi 3. Bogor: Mitra Wacana Media. https://jurnalmahasiswa.unesa.ac.id/index.php/jim/article/download/10168/9936 